\title{
Role of CXCL16 in BLM-induced epithelial- mesenchymal transition in human A549 cells
}

\begin{abstract}
Alveolar epithelial cells play an essential role in the initiation and progression of pulmonary fibrosis, and the occurrence of epithelial-mesenchymal transition (EMT) may be the early events of pulmonary fibrosis. Recent studies have shown chemokines are involved in the complex process of EMT, and CXC chemokine ligand 16 (CXCL16) is also associated with many fibrosis-related diseases. However, whether CXCL16 is dysregulated in alveolar epithelial cells and the role of CXCL16 in modulating EMT in pulmonary fibrosis has not been reported. In this study, we found that CXCL16 and its receptor C-X-C motif chemokine receptor 6 (CXCR6) were upregulated in bleomycin induced EMT in human alveolar type II-like epithelial A549 cells. Synergistic effect of CXCL16 and bleomycin in promoting EMT occurrence, extracellular matrix (ECM) excretion, as well as the pro-inflammatory and pro-fibrotic cytokines productions in A549 cells were observed, and those biological functions were impaired by CXCL16 siRNA. We further confirmed that CXCL16 regulated EMT in A549 cells via the TGF- $\beta 1 / S m a d 3$ pathways. These results indicated that CXCL16 could promote pulmonary fibrosis by promoting the process of EMT via the TGF- $\beta 1 / \mathrm{Smad} 3$ signaling pathway.
\end{abstract}

Keywords: Pulmonary fibrosis, Chemokines, CXCL16, Epithelial-mesenchymal transition

\section{Background}

Pulmonary fibrosis is a progressive and destructive lung disease with various causes, which seriously endangers patients' health and life. It is now well-recognized that "pulmonary fibrosis" covers a broad range of lung diseases, including most topically the idiopathic pulmonary fibrosis (IPF), and connective tissue disease-associated interstitial lung disease (CTD-ILD) [1]. With high morbidity and mortality, the median survival time of IPF after diagnosis was about $2-3$ years in the absence of efficient treatment [2]. Combined ILD is an important predictor

\footnotetext{
*Correspondence: liu-xiangyuan@263.net; qryang720@163.com

†Qingrui Yang and Xiangyuan Liu shared senior authorship

${ }^{1}$ Department of Rheumatology and Immunology, Shandong

Provincial Hospital, Cheeloo College of Medicine, Shandong University, Jinan 250021, Shandong, China

${ }^{3}$ Department of Rheumatology and Immunology, Peking University Third Hospital, Beijing 100191, China

Full list of author information is available at the end of the article
}

of outcomes in patients with CTD, and it is also one of the most common causes of death in patients with CTD $[3,4]$. Due to the lack of effective treatment to improve its adverse outcome, it is urgent to deepen the study of the mechanism of pulmonary fibrosis and develop new treatment strategies on this basis.

The pathogenesis and pathological process of pulmonary fibrosis is always divided into four parts: injury of the lung tissue with various causes, release of diverse proinflammatory and pro-fibrotic mediators, destruction of the tissue structures and the subsequent tissue repairs. However, repeated and abnormal repair of the lung tissue results in the disorder of the internal environment and excessive deposition of extracellular matrix (ECM), and finally leads to the occurrence of pulmonary fibrosis [5]. Some studies have shown that alveolar macrophages, alveolar epithelial cells and pulmonary interstitial cells all participate in the development of pulmonary fibrosis by secreting inflammatory cytokines and mediators, directly 
or indirectly [6]. Among them, alveolar epithelial cells play a key role in the initiation and progression of pulmonary fibrosis, and it may undergo EMT to contribute to foci development in the early in the fibrotic disease [7]. Myofibroblasts (MFB) are regarded as the main perpetrators of fibrosis as they appear to be the major source of ECM proteins, and EMT is an important source of myofibroblasts in fibrosis related diseases [8]. In vivo lineage-tracing studies have showed that about $1 / 3$ of MFB originated from epithelial cells in the pulmonary fibrosis models prepared by single bleomycin (BLM) injection [9], while about $1 / 2$ of MFB originated from epithelial cells in the models prepared by multiple BLM injection [10]. Hence, to explore the underlying mechanisms of EMT in pulmonary fibrosis may provide an important basis for the treatment of pulmonary fibrosis and related diseases.

In the past few decades, some new understandings and important advances have been made in the study of the molecular mechanisms of EMT, especially the role of chemokines in the complex EMT process. For example, the CXC chemokine 7 (CXCL7) inhibits growth and migration of oral tongue squamous cell carcinoma cells via the EMT signaling pathway [11], CC-Chemokine Ligand 18 (CCL18) induces EMT in lung cancer and elevates the invasive potential [12], and CXC chemokine 9 (CXCL9) regulates TGF- $\beta 1$-induced EMT in human alveolar epithelial cells [13]. CXCR6, the only receptor for CXCL16, predicts poor prognosis and promotes cancer metastasis in gastric cancer through EMT induction [14]. Specifically, we found that CXCL16/CXCR6 in the lung tissues of Saline-treated wild-type mice was only expressed in a small amount in the airway epithelial cells and the vascular smooth muscle cells, while CXCL16/ CXCR6 in the lung tissues of BLM-treated wild-type mice was widely expressed in the airway and alveoli epithelium cells and the lung interstitium, accompanied by the infiltration of CXCR6 positive lymphocytes in the alveolar cavity (Additional file 1: Fig. S1). However, whether CXCL16 is also dysregulated in the human alveolar epithelial cells and the role of CXCL16 in modulating EMT in pulmonary fibrosis has not been reported. In this study, the potential role of CXCL16 in regulating EMT in BLM-induced pulmonary fibrosis in human A549 cells was investigated.

\section{Materials and methods \\ Cell culture}

Human alveolar type II-like epithelial A549 cells were purchased from the National Infrastructure of Cell Line Resource (Beijing, China). A549 cells were maintained in Dulbecco Modified Eagle Medium (DMEM) containing
$10 \%$ fetal bovine serum (FBS), and were cultured at $37^{\circ} \mathrm{C}$ in a humidified incubator with $5 \% \mathrm{CO}_{2}$.

\section{Cell viability assay}

A549 cells $\left(5 \times 10^{3} /\right.$ well $)$ were seeded in 96 -well plates for $4 \mathrm{~h}$ and then incubated with different concentrations of BLM (Selleck Chemicals, USA) or CXCL16 (PeproTech, USA) for $24 \mathrm{~h}$. The effect of BLM or CXCL16 on cell viability was detected by using the CellTiter $96{ }^{\circledR}$ AQueousOne Solution Cell Proliferation Assay (MTS assay, USA) according to the manufacturer's protocol.

\section{Real-time PCR}

Total RNA was extracted by using the TRIzol reagent (Invitrogen, USA) according to the manufacturer's proto$\mathrm{col}$, and $1 \mu \mathrm{g}$ of total RNA was reverse-transcribed into cDNA by using the FastQuant RT Kit (Tiangen, China). RT-PCR was carried out by using the QuantStudio ${ }^{\mathrm{TM}} 5$ Real-Time PCR System (Thermo Fisher Scientific, USA) with Talent qPCR PreMix (Tiangen, China). For each experiment, at least three parallel measurements were carried out, and GAPDH served as a loading control. The specific primers used in this study were shown in Additional file 1: Table S1.

\section{Western blot}

Total protein was harvested by using the RIPA buffer and was determined with a BCA protein assay kit. The protein samples were separated $(40 \mu \mathrm{g})$ via $10 \%$ SDS-PAGE and transferred to PVDF membranes (Millipore, USA). After blocking with 5\% non-fat milk for $2 \mathrm{~h}$, the membranes were incubated with the relevant antibody for $12-14 \mathrm{~h}$ at $4{ }^{\circ} \mathrm{C}$ and were incubated with the specific secondary antibodies for $1 \mathrm{~h}$ at room temperature. The membranes were scanned using an Odyssey Sa Imaging System (LI-COR Biosciences, USA). GAPDH was used as loading control. The specific antibodies used in this study were shown in Additional file 1: Table S2.

\section{Immunofluorescence}

A549 cells $\left(5 \times 10^{3} /\right.$ well $)$ were seeded in confocal dishes (NEST, China) and were treated with BLM for $24 \mathrm{~h}$. After washed with PBS, the cells were fixed with $4 \%$ paraformaldehyde for $30 \mathrm{~min}$, and blocked with $2 \%$ goat serum for $1 \mathrm{~h}$ at room temperature. The cells were incubated overnight at $4{ }^{\circ} \mathrm{C}$ with specific antibodies (CXCL16, 1:100; CXCR6, 1:100), and then incubated with 488-labeled goat anti-rabbit IgG for $1 \mathrm{~h}$ at room temperature. DAPI (SIGMA) was counter-stained and images were acquired on a laser confocal microscope (Leica TCS SP8, Germany). 


\section{Enzyme-linked immunosorbent assay (ELISA)}

Levels of interleukin-6 (IL-6), interleukin-8 (IL-8), interleukin-1 $\beta$ (IL-1 $\beta$ ) and the tumor necrosis factoralpha (TNF- $\alpha)$ in cell culture supernatant were separately detected by the Human High Sensibility ELISA Kit (MultiSciences, China). Soluble CXCL16 (sCXCL16) and the transforming growth factor- $\beta 1$ (TGF- $\beta 1$ ) in cell culture supernatant were separately detected by the Human CXCL16/TGF- $\beta 1$ Immunoassay Quantikine ELISA kit (R\&D Systems, USA) according to the manufacturer's protocol.

\section{Transient transfection}

CXCL16 siRNA (Santa Cruz, USA), Scramble control and positive control (Ribobio, China) were transfected into A549 cells by using Lipofectamine RNAiMAX (Invitrogen, USA) following the manufacturer's instructions, and the transfection efficiency was detected by western blot $48 \mathrm{~h}$ later.

\section{Statistical analysis}

Statistical analyses were performed with SPSS (version 22.0) and Graphad Prism (version 7.0). All experiments were repeated at least three times. Data was expressed as mean \pm standard deviation (SD). Analysis of variance (ANOVA) with post hoc Dunnett's correction was performed to compare continuous variables. The Mann-Whitney U-test was used for non-parametric comparisons. $\mathrm{P}<0.05$ was considered statistical significant.

\section{Results \\ BLM-treated A549 cells have undergone EMT}

Results from the MTS assay indicated that BLM inhibited the proliferation of A549 cells in a dose-dependent manner and the appropriate concentrations of BLM in treating A549 cells for $24 \mathrm{~h}$ were $200 \mu \mathrm{g} / \mathrm{ml}$ (Fig. 1a). Next, phenotypic markers associated with EMT including $\alpha$-SMA and E-cadherin was detected by PCR and western blot. Results showed that with the increase of the BLM concentrations, increased levels of $\alpha-S M A$ expression and decreased levels of E-cadherin expression have been observed, both in mRNA and protein levels (Fig. 1b-f). These data confirmed that BLM -treated human A549 cells have undergone EMT.

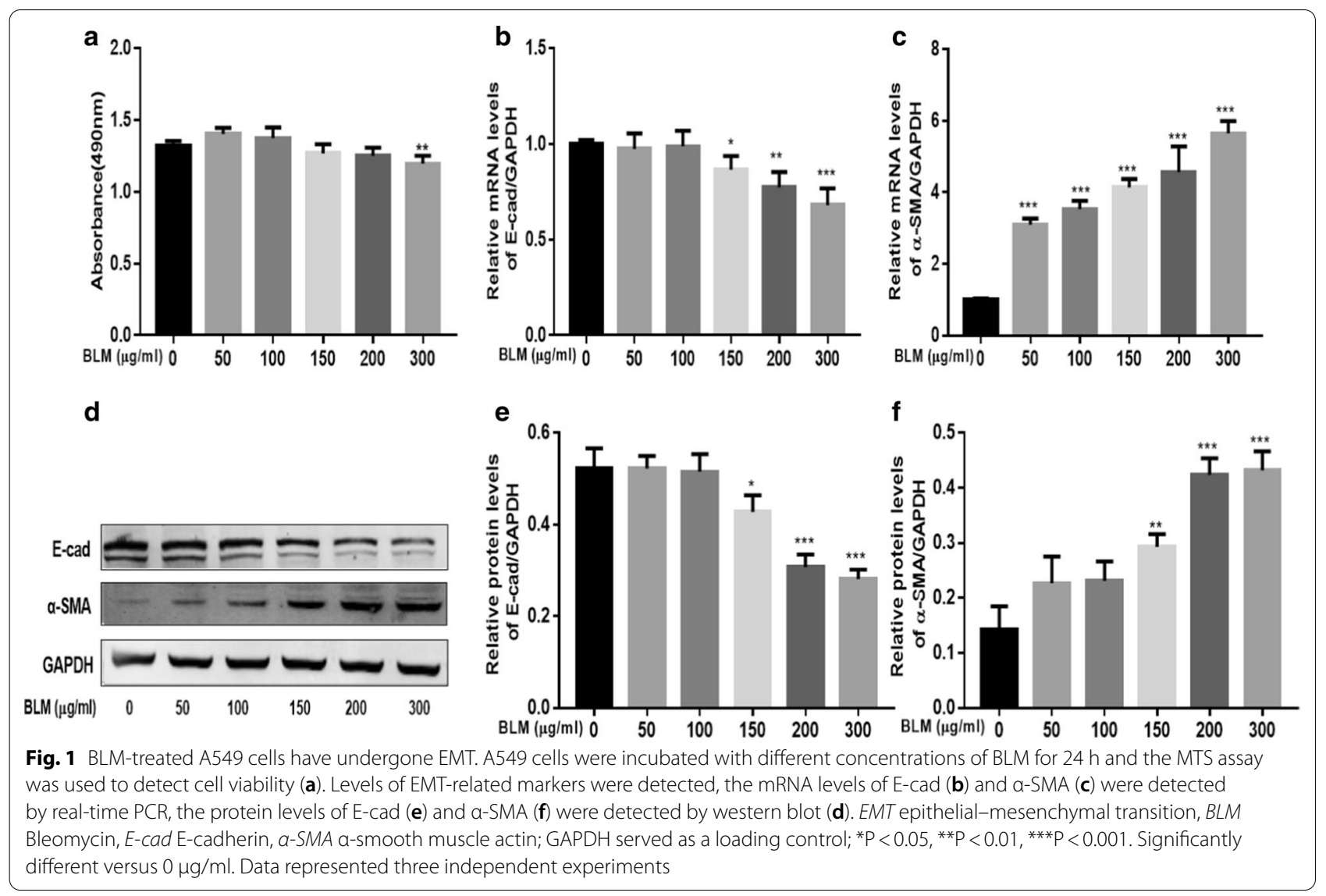


CXCL16 and its receptor CXCR6 were upregulated in BLM-induced EMT in human A549 cells

Next, we detected the expression of CXCL16 and its receptor CXCR6 in BLM-induced EMT in A549 cells, by RT-PCR, western blot and immunofluorescence. We found that mRNA levels of CXCL16 and CXCR6 were markedly increased in A549 cells when treated with BLM, with similar results obtained in western blot and immunofluorescence (Fig. 2). The results indicated that CXCL16 and its receptor CXCR6 were up-regulated in A549 cells and might participate in the development of BLM-induced EMT in human A549 cells.
Synergistic effect of CXCL16 and BLM on EMT occurrence, ECM excretion, pro-inflammatory and pro-fibrotic cytokines productions in human A549 cells

To further examine whether CXCL16 has a synergistic effect with BLM on the EMT occurrence and ECM excretion in human A549 cells, the cells were co-stimulated with CXCL16 and BLM. First, the appropriate concentrations of CXCL16 in treating A549 cells for $24 \mathrm{~h}$ were $200 \mathrm{ng} / \mathrm{ml}$, as confirmed by the MTS assay. Co-stimulation of $200 \mathrm{ng} / \mathrm{ml} \mathrm{CXCL16} \mathrm{and} 200 \mu \mathrm{g} / \mathrm{ml}$ BLM was implemented for $24 \mathrm{~h}$ in A549 cells. Results showed that the up-expression of $\alpha$-SMA and the down-expression

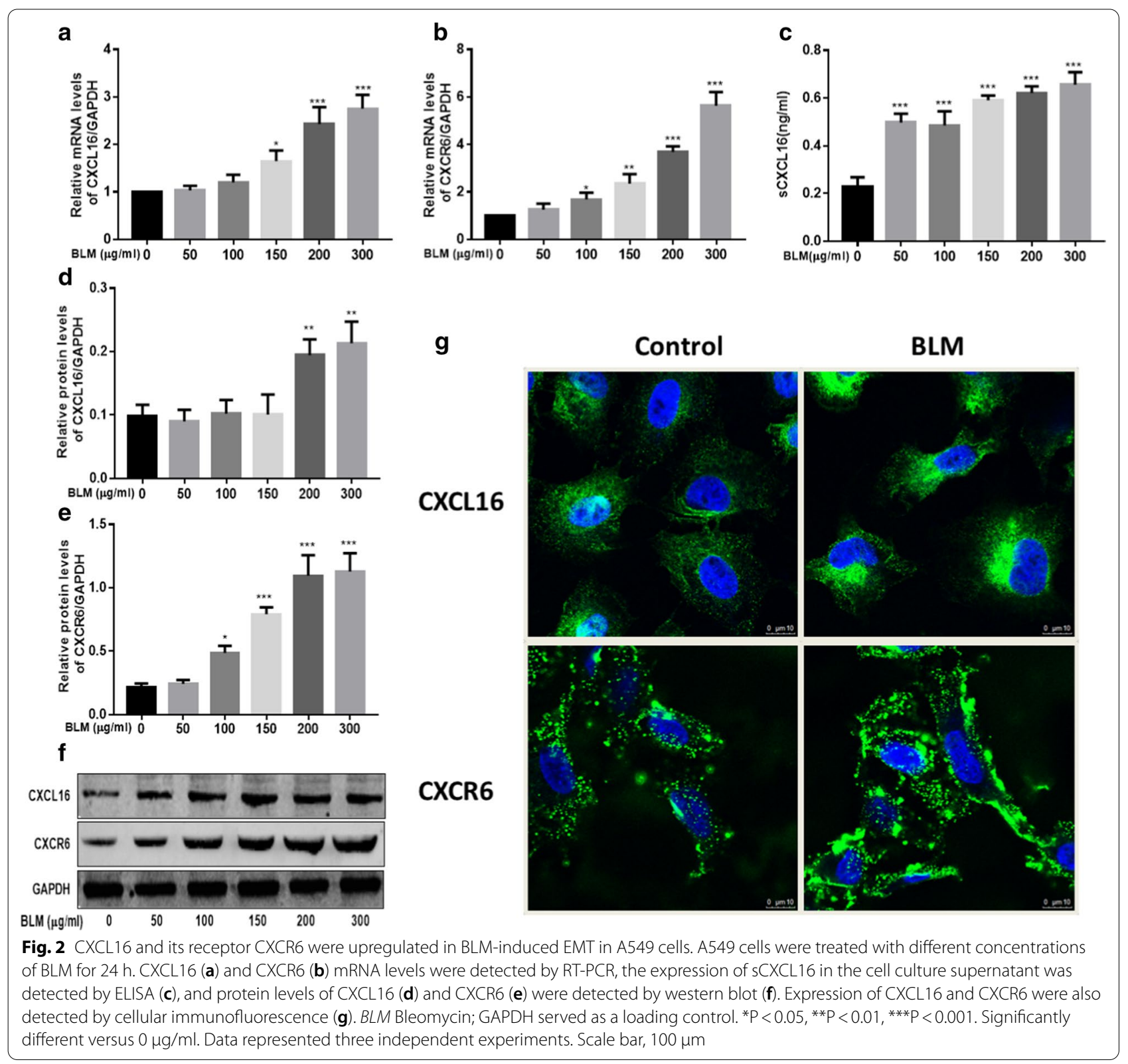


of E-cadherin was observed in the co-stimulation group, compared with single stimulation with BLM, which indicated that CXCL16 and BLM synergistically promoted the occurrence of EMT (Fig. 3a, b). Through the processes of EMT, epithelial cells often lose their own properties and present as a mesenchymal phenotype with the ability to secrete collagen. Thus, the expression of collagen I (COLI) was detected, and the expression of COLI in both mRNA and protein levels were found to be elevated (Fig. 3c, e). We also found that IL-6, IL-8, IL-1 $\beta$, TNF- $\alpha$ and TGF- $\beta 1$ mRNA and protein levels were markedly increased in A549 cells in the co-stimulation group, compared with the BLM group (Fig. 3h-o). The above data indicated that CXCL16 had a synergistic effect with BLM in promoting EMT occurrence, ECM excretion, pro-inflammatory and pro-fibrotic cytokines productions in A549 cells.

\section{CXCL16 regulated BLM-induced EMT and ECM excretion in human A549 cells}

To investigate the specific role of CXCL16 in BLMinduced EMT, we silenced the expression of CXCL16 by transfecting A549 cells with CXCL16 siRNA, and the inhibitory efficiency of CXCL16 siRNA could be seen

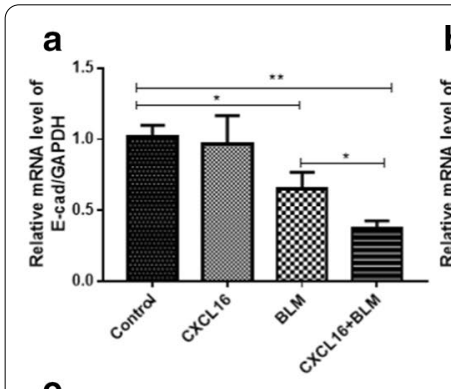

e

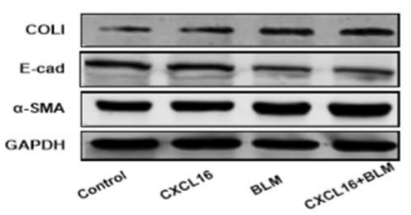

h
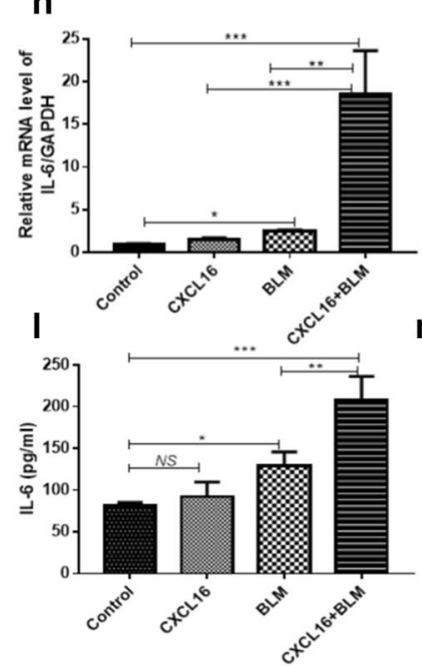

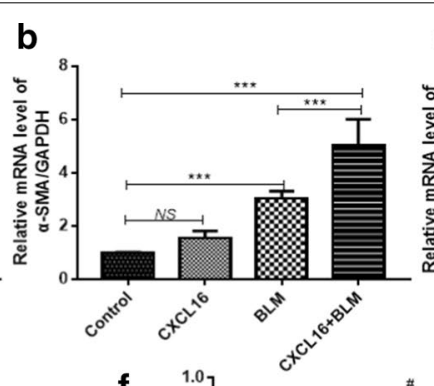

f

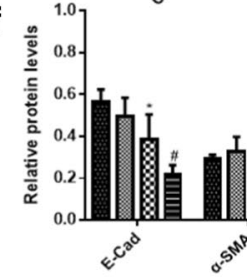

i
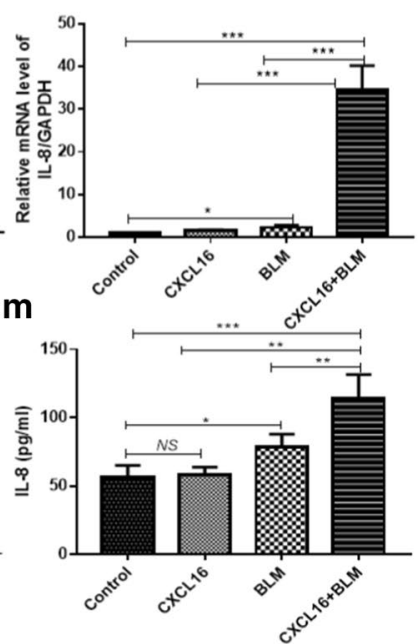
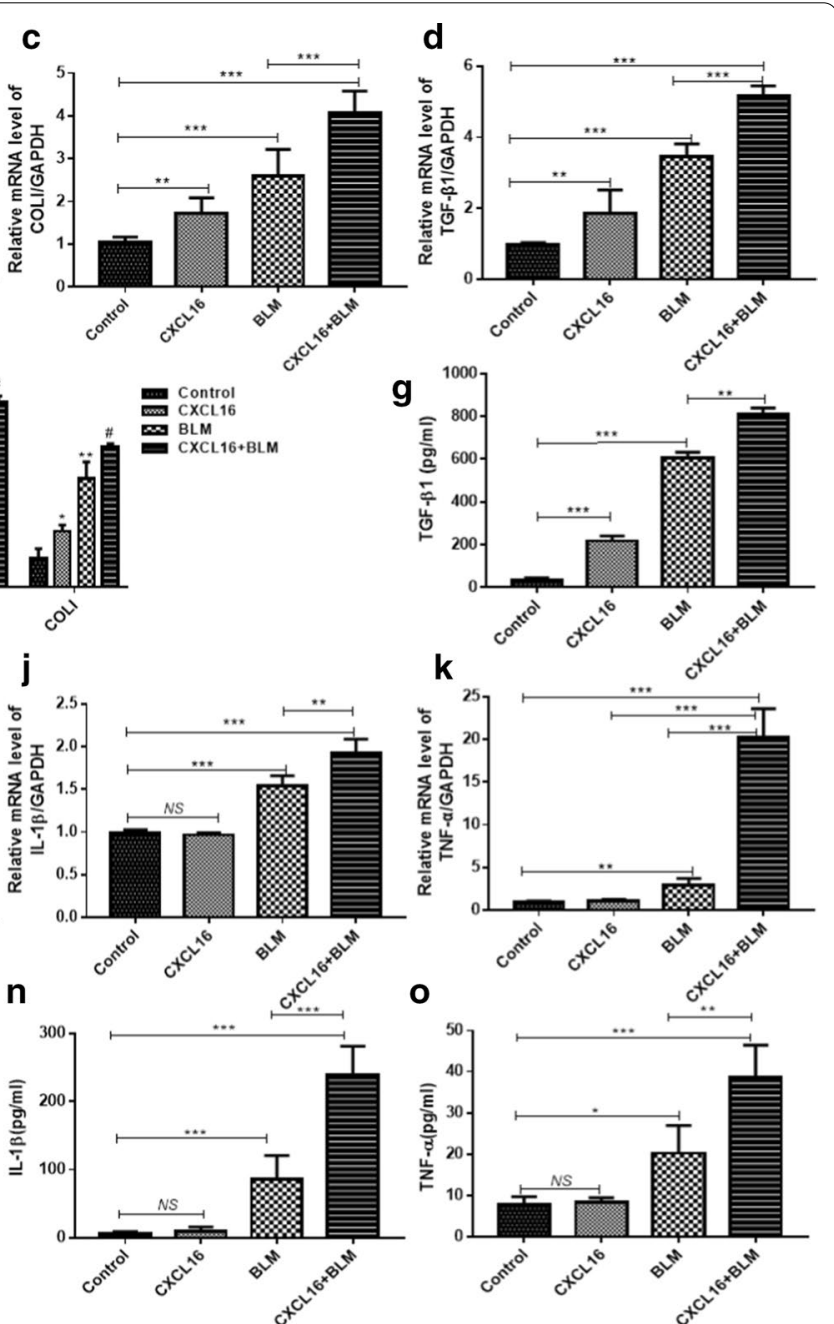
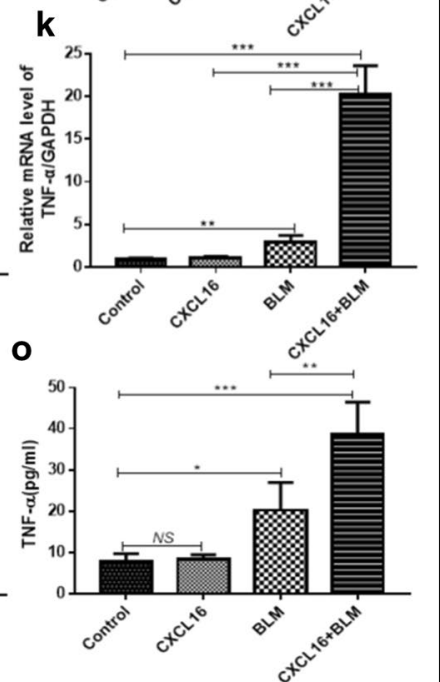

Fig. 3 After co-stimulation of CXCL16 $(200 \mathrm{ng} / \mathrm{ml})$ and BLM $(200 \mu \mathrm{g} / \mathrm{ml})$ in A549 cells for $24 \mathrm{~h}$, the mRNA levels of E-cad (a), a-SMA (b),COLI (c), TGF- $\beta 1$ (d), IL-6 (h), IL-8 (i), IL-1 $\beta(\mathbf{j})$ and TNF- $\alpha(\mathbf{k})$ were determined by RT-PCR and the protein levels of E-cad, $a-S M A$ and COLI were determined by western blot $(\mathbf{e}, \mathbf{f})$. The levels of TGF- $\beta 1(\mathbf{g}), \mathrm{IL}-6(\mathbf{I}), \mathrm{LL}-8(\mathbf{m}), \mathrm{IL}-1 \beta(\mathbf{n})$ and TNF- $\mathrm{a}(\mathbf{o})$ in the supernatants of A549 cells were detected using the corresponding ELISA kit. BLM Bleomycin, E-cad E-cadherin, $\alpha$-SMA a-smooth muscle actin, TGF- $\beta 1$ the transforming growth factor- $\beta 1$, COLI collagen I, IL-6 interleukin-6, IL-8 interleukin-8, IL-1 $\beta$ interleukin-1 $\beta$, TNF- $\alpha$ the tumor necrosis factor-alpha. GAPDH served as a loading control. ${ }^{*} P<0.05$, ${ }^{* * P}<0.01,{ }^{* *} \mathrm{P}<0.001,{ }^{\#} P<0.05$; NS not significant. ${ }^{*}$ Significantly different versus the control group. "Significantly different versus the BLM group. Data represented three independent experiments 
in Additional file 1: Fig. S2. RT-PCR, western blot and ELISA results showed that expression of CXCL16 was obviously down-regulated by CXCL16 siRNA in A549 cells. Expression of $\alpha$-SMA and E-cadherin was measured in unstimulated and BLM stimulated A549 cells and the results showed that when CXCL16 was silenced, the expression of $\alpha$-SMA was reduced (Fig. $4 \mathrm{~b}, \mathrm{e}$ ), while the expression of E-cadherin was increased (Fig. 4a, d). Similarly, silencing CXCL16 with siRNA also reduced the expression of COLI induced by BLM, both in mRNA and protein levels (Fig. 4c, f). The above data indicated that CXCL16 might play an important role in modulating BLM-induced EMT and ECM excretion in human A549 cells.

\section{CXCL16 siRNA reduced production of pro-inflammatory and pro-fibrotic cytokines in human A549 cells}

Pro-inflammatory and pro-fibrotic cytokines forms a complex regulation network during the occurrence and development of pulmonary fibrosis, whether CXCL16 modulate BLM-induced pulmonary fibrosis via promoting secretion of the pro-inflammatory and pro-fibrotic cytokines is still unknown. Expression of IL-6, IL-8, IL- $1 \beta$, TNF- $\alpha$ and TGF- $\beta 1$ was measured in unstimulated and BLM stimulated A549 cells and the results showed that after silencing of CXCL16, the expression of IL-6,
IL-8 and TGF- $\beta 1$ were markedly reduced in BLM stimulated A549 cells (Fig. 5a, c, e), while the expression of IL- $1 \beta$ and TNF- $\alpha$ had no obvious changes (Fig. $5 b, d$ ). Thus, we speculated that CXCL16 might modulate BLMinduced IL-6, IL-8 and TGF- $\beta 1$ expression in A549 cells.

\section{CXCL16 may regulate EMT in human A549 cells via the TGF- $\beta 1 /$ Smad 3 pathways}

To further investigate the potential pathway by which CXCL16 regulates BLM-induced EMT, we detected the expression of TGF- $\beta 1$ and Smad3 when CXCL16 was silenced in BLM-stimulated A549 cells. As shown in the results, the expression of TGF- $\beta 1$ and the phosphorylation of Smad3 were markedly reduced when CXCL16 was silenced by siRNA in the A549 cells (Fig. 5e, h for TGF$\beta 1$; Fig. 6 for Smad3). These data indicated that CXCL16 might regulate the EMT process via the TGF- $\beta 1 / \mathrm{Smad} 3$ pathways.

\section{Discussion}

Pulmonary fibrosis is the fundamental to the pathogenesis of many chronic pulmonary diseases, and always characterized by progressive decline in the lung functions. Although the molecular mechanism of pulmonary fibrosis remains unclear, the role of EMT in the pathogenesis of pulmonary fibrosis has become a new research

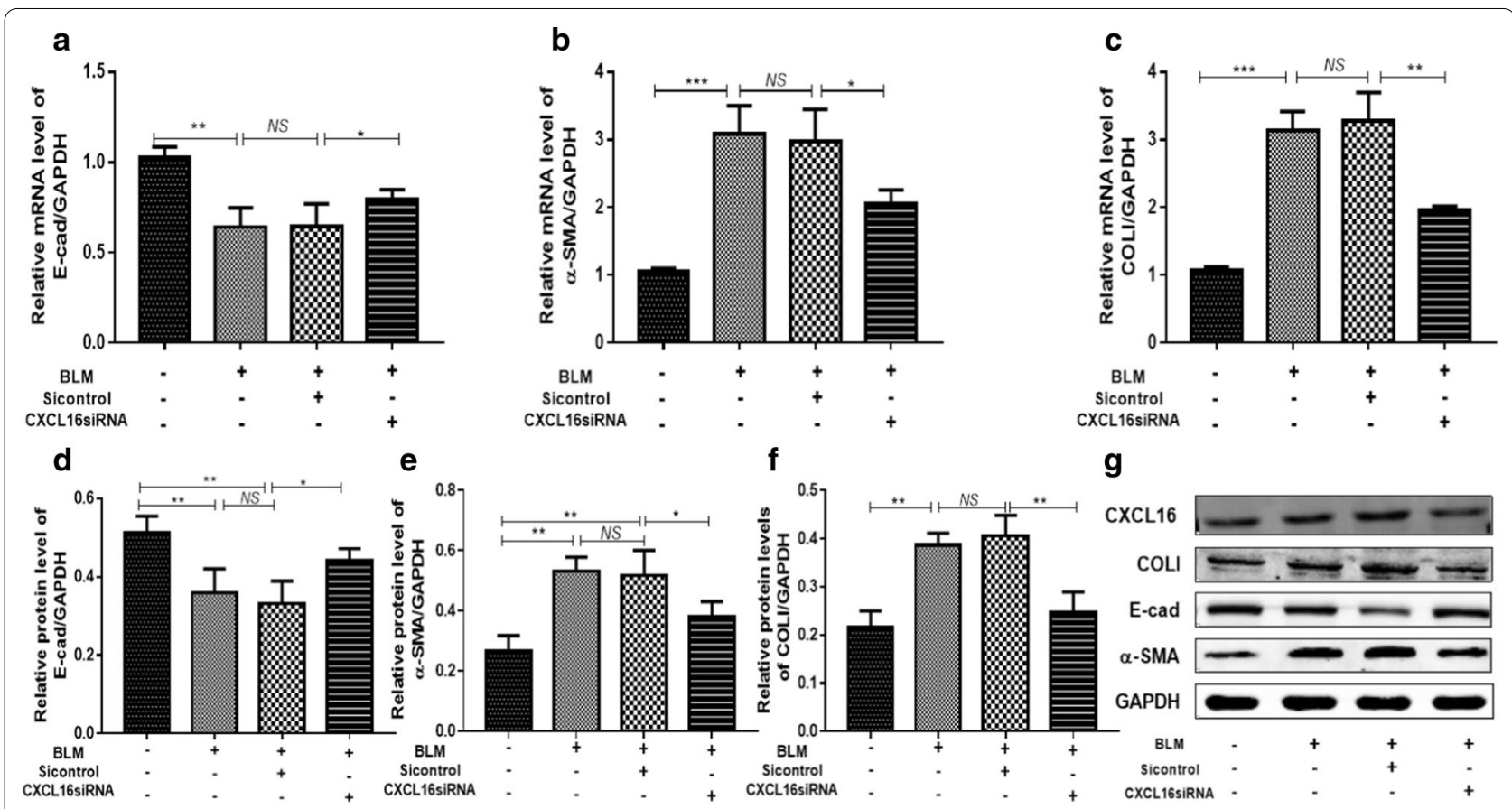

Fig. 4 CXCL16 regulated BLM-induced EMT and ECM excretion in A549 cells. CXCL16 siRNA was transfected into A549 cells for $12 \mathrm{~h}$, after treated the cells with $200 \mu \mathrm{g} / \mathrm{ml}$ BLM for $24 \mathrm{~h}$. The mRNA levels of E-cad (a), a-SMA (b) and COLI (c) was determined by RT-PCR and the protein levels of E-cad (d), a-SMA (e) and COLI (f) was determined by western blot (g). BLM Bleomycin, E-cad E-cadherin, a-SMA a-smooth muscle actin, COLI collagen I; GAPDH served as a loading control. ${ }^{*} \mathrm{P}<0.05$, ${ }^{* *} \mathrm{P}<0.01,{ }^{* *} \mathrm{P}<0.001$; ns not significant. Data represented three independent experiments 

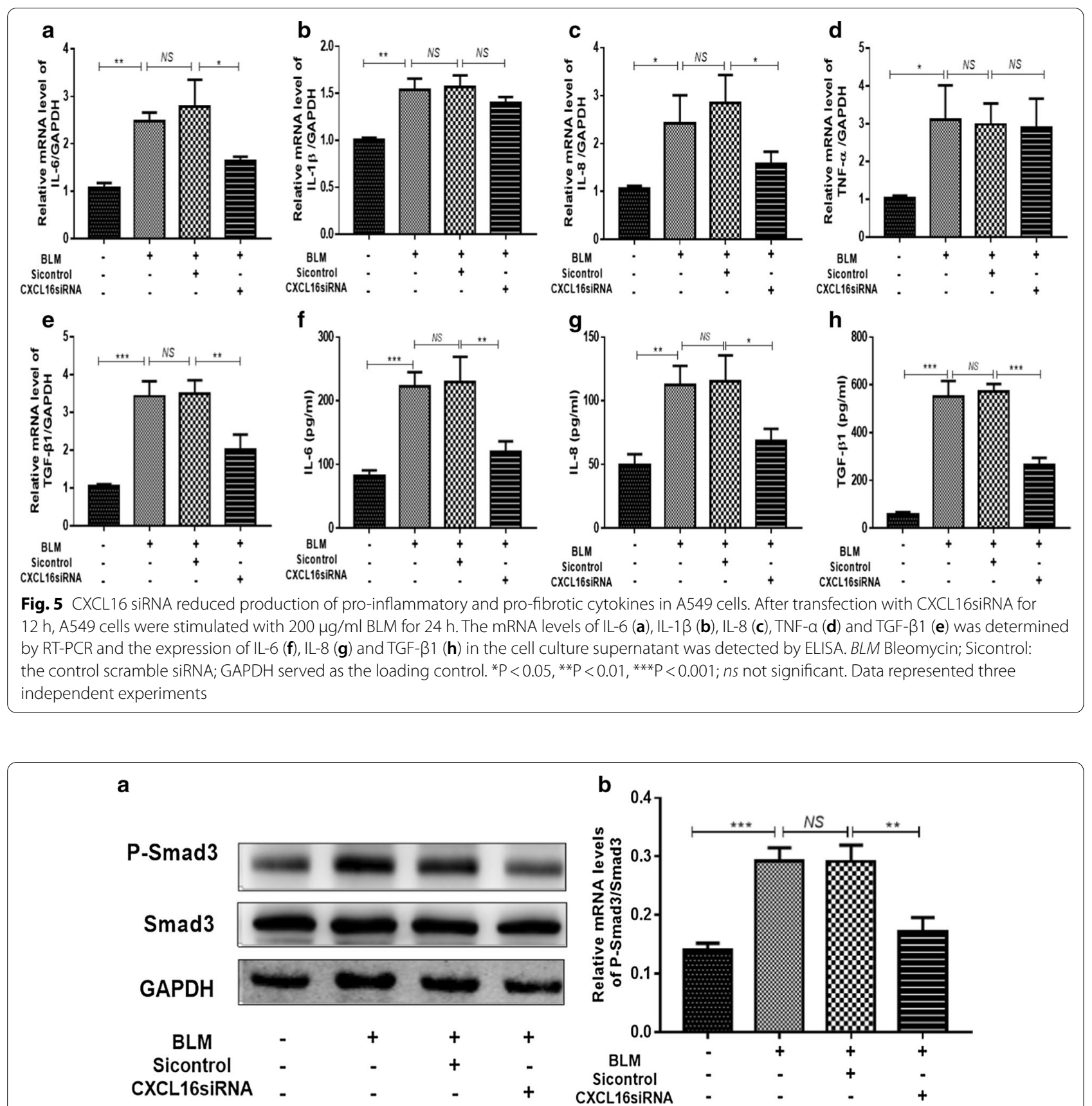

Fig. 6 CXCL16 may regulate EMT in A549 cells via the TGF- $31 / S m a d 3$ pathways. P-Smad3 and Smad3 protein levels in A549 cells were detected by western blot after silencing of $C X C L 16$. GAPDH served as a loading control. ${ }^{* *} P<0.01$, ${ }^{* *} P<0.001$; NS not significant. Data represented three independent experiments

hotspot $[15,16]$. A recent study has demonstrated that the main features of fibrosis were the activation of fibroblast and the deposition of ECM, which occurs concomitant with proliferation and aggregation of MFB [17]. MFB acts as the main source of collagen in active pulmonary fibrosis and the main effector cells of pulmonary fibrosis [18]. Three sources of activated MFB have been found, including the proliferation and phenotypic transformation of fibroblasts around the injury site [19], the activation of EMT and the migration of fibrocytes [20,21]. During the process of EMT, the down-regulation of epithelial markers (e.g., E-cadherin, ZO-1) and the up-regulation of mesenchymal markers (e.g., $\alpha$-SMA, COLI) was observed, and epithelial cells loses polarity and recover 
its ability on migration, invasion and collagen production [22]. EMT is always involved in embryonic development, as well as in several pathological conditions, such as endometriosis, chronic obstructive pulmonary disease, metastasis of tumors and fibrosis in tissues or organs [15, 23-25]. It has been reported that CXCR6 could promote tumor metastasis through EMT [14]. CXCL16/CXCR6 participates in multiple organ fibrosis and plays a positive role in the occurrence of fibrotic diseases. But the previous studies of CXCL16/CXCR6 in fibrotic diseases mainly focused on the release of inflammatory factors, the aggregation and activation of immune cells and the migration of fibrocytes [26-28]. In our previous studies, sCXCL16 was overexpressed in serum of patients with rheumatoid arthritis-related interstitial lung disease, suggesting that it may play a role in the process of pulmonary fibrosis [29]. However, little is known whether CXCL16 is dysregulated in alveolar epithelial cells and the role of CXCL16 in modulating EMT in pulmonary fibrosis.

Repeated damage to the alveolar epithelial cells induced by various harmful factors has been accepted as the first and foremost cause of pulmonary fibrosis and complex networks of cytokines are involved in this process, as well as the subsequent tissue repair and fibrosis [30]. Here, a well-validated model of EMT in the A549 human alveolar cell line was used to study the mechanism of pulmonary fibrosis, for which a suite of morphological, phenotypic and functional markers and outcomes have been well characterized [31-33]. BLM is widely used as an inducer of pulmonary fibrosis in animal models [34], and similar effects were validated in vitro experiments, and EMT characteristics were detected in BLM treated A549 cells $[35,36]$. Our research discovered that CXCL16 and its receptor CXCR6 were upregulated in BLM-induced EMT in the human A549 cells. We further verified the synergistic effect of CXCL16 and BLM in the process of pulmonary fibrosis.

To better understand the role of CXCL16 in BLMinduced EMT, we silenced the expression of CXCL16 by specific siRNA, then the occurrence of EMT and the production of collagens markedly reduced in BLM stimulated A549 cells. Our data indicated that CXCL16 might play an important role in modulating BLM-induced EMT and ECM excretion in A549 cells. Increasing evidence suggests that the important stimulator of collagen accumulation in pulmonary fibrosis is the increased production of pro-inflammatory and pro-fibrogenic cytokines/ chemokines. The activation of MFB may be regulated by a complex network of various cytokines in local microenvironment. Some cytokines are involved in local injury and inflammation (e.g., IL-6, IL-1 $\beta$, IL- 8 and TNF- $\alpha$ ), while others, such as TGF- $\beta 1$, is mainly involved in tissue repair and fibrosis $[37,38]$. Meanwhile, CXCL16 is closely related to the occurrence of inflammatory diseases and inflammatory-related tumors $[39,40]$, so here we detected the expression of above indicators in BLMinduced EMT in A549 cells. After silencing of CXCL16, the expression of IL- 6, IL- 8 and TGF- $\beta 1$ were markedly reduced in BLM stimulated A549 cells. Thus, we speculated that CXCL16 might modulate BLM-induced IL-6, IL- 8 and TGF- $\beta 1$ expression in the A549 cells during EMT process.

Alveolar epithelial cells are one of the main cells that produce and secrete TGF- $\beta 1$ in pulmonary fibrosis, and TGF- $\beta 1$ is known to be the most critical fibrogenic factor, which could lead to the synthesis of collagen and other matrix proteins in large quantities. At present, the signal transduction pathways of TGF- $\beta 1$ are mainly classified into Smad protein-dependent and -independent signaling and the TGF- $\beta 1$-induced Smad3 signaling pathway has been considered to be one of the most important mechanisms of pulmonary fibrosis progression [41-43]. Further study of the regulatory mechanism of CXCL16 in BLM-induced EMT has been carried out and we found that the expression of TGF- $\beta 1$ and the phosphorylation of Smad3 were significantly reduced in A549 cells when CXCL16 was silenced, which indicated that CXCL16 may regulate EMT in A549 cells via the TGF- $\beta 1 /$ Smad3 signaling pathway.

There were also some limitations to the present study. First, A549 is a non-small-cell lung cancer cells, although it retains the characteristics of typical type II alveolar epithelial and acts as a well-studied model of EMT, it still behaves differently from normal epithelial cells in many occasions [44, 45]. Additional prospective studies with primary human lung alveolar type 2 cells are necessary to validate the role of CXCL16 in BLM-induced EMT. Second, we did not investigate the possible relationship between CXCL16 and other signal transduction pathways in EMT such as Wnt, Notch, Hedgehog, etc. Additional studies (e.g. in primary epithelial cells, animal models, human tissues) are necessary to elucidate the functional role of CXCL16 in modulating EMT in pulmonary fibrosis.

\section{Conclusions}

In summary, we found that CXCL16 and its receptor CXCR6 were upregulated in BLM-induced EMT and synergistic effect of CXCL16 and BLM on the occurrence of EMT, the excretion of ECM, as well as the production of pro-inflammatory and pro-fibrotic cytokines in A549 cells have been observed. In addition, our study further elucidated that CXCL16 might regulate EMT in A549 cells via the TGF- $\beta 1 /$ Smad3 pathways. Our results establish a new mechanism of BLM-induced EMT and may provide an important basis for the treatment of 
pulmonary fibrosis and related diseases. Further research is necessary to assess the role of CXCL16 in pulmonary fibrosis and its potential as a therapeutic target in fibrosis-related diseases.

\section{Supplementary Information}

The online version contains supplementary material available at https://doi. org/10.1186/s12931-021-01646-7.

Additional file 1: Table S1. Information of the primer sequence. Table S2. Information of the antibodies. Fig. S1. CXCL16 and CXCR6 expression levels in the lung tissues of BLM-induced pulmonary fibrosis mice models. Representative serial lung sections from BLM-WT group and Saline-WT group were stained for CXCL16 and CXCR6. The results of immunohistochemistry showed that CXCL16/CXCR6 in the lung tissue of Salin-WT group was only expressed in a small amount in airway epithelial cells and vascular smooth muscle cells, while CXCL16/CXCR6 in the lung tissue of BLM-WT group was widely expressed in airway and alveoli epithelium cells and lung interstitium, accompanied by the infiltration of CXCR6 positive lymphocytes in the alveolar cavity. Saline-WT: Saline-treated wild-type mice; BLM-WT: Bleomycin-treated wild-type mice. $N=5$, Scale bar $=100 \mu \mathrm{m}$. Fig. S2. Inhibitory efficiency of CXCL16 siRNA was observed by RT-PCR, western blot and ELISA $48 \mathrm{~h}$ after siRNA transfection. Sicontrol: the control scramble siRNA; Positive control: GAPDH siRNA; GAPDH served as a loading control. ${ }^{*} P<0.05,{ }^{* * P}<0.01$, ${ }^{* * * P}<0.001$. ns, not significant. Data represented three independent experiments.

\section{Abbreviations}

EMT: Epithelial-mesenchymal transition; CXCL16: CXC chemokine ligand 16; CXCR6: C-X-C motif chemokine receptor 6; ECM: Extracellular matrix; BLM: Bleomycin; L-6: Interleukin-6; IL-1 $\beta$ : Interleukin-1 $\beta$; TNF-a: Tumor necrosis factor-alpha; TGF- $\beta 1$ : The transforming growth factor- $\beta 1$; $a-S M A$ : A-smooth muscle actin; COLl: Collagen I.

\section{Acknowledgements}

Not applicable.

\section{Authors' contributions}

ZM, CM, QZ and YB performed experiments, analyzed data and reviewed the manuscript. QY, XL and KM provided funds and project design. All authors read and approved the final manuscript.

\section{Funding}

This work was supported by the National Natural Science Foundation of China (No. 81771744 and 81671605) and Key Research and Development Program of Shandong Province (Grant numbers 2017GSF18134).

\section{Availability of data and materials}

The datasets used during the current study are available from the corresponding author on reasonable request.

\section{Ethics approval and consent to participate}

Not applicable.

\section{Consent for publication}

Not applicable.

\section{Competing interests}

The authors declare that they have no competing interests.

\section{Author details}

1 Department of Rheumatology and Immunology, Shandong Provincial Hospital, Cheeloo College of Medicine, Shandong University, Jinan 250021 Shandong, China. ${ }^{2}$ Department of Rheumatology and Immunology, Shandong Provincial Hospital Affiliated to Shandong First Medical University, Jinan 250021, Shandong, China. ${ }^{3}$ Department of Rheumatology and Immunology, Peking University Third Hospital, Beijing 100191, China. ${ }^{4}$ Department of Central Laboratory, Shandong Provincial Hospital Affiliated to Shandong First Medical University, Jinan 250021, Shandong, China. ${ }^{5}$ Department of Pathology, Qilu Hospital, Shandong University, Jinan 250012, China.

Received: 22 October 2020 Accepted: 31 January 2021 Published online: 06 February 2021

\section{References}

1. Margaritopoulos GA, Kokosi MA, Wells AU. Diagnosing complications and co-morbidities of fibrotic interstitial lung disease. Expert Rev Respir Med. 2019;13(7):645-58. https://doi.org/10.1080/17476348.2019.1632196.

2. Sharif R. Overview of idiopathic pulmonary fibrosis (IPF) and evidencebased guidelines. Am J Manag Care. 2017;23(11 Suppl):S176-82.

3. Fischer A, du Bois R. Interstitial lung disease in connective tissue disorders. Lancet. 2012;380(9842):689-98. https://doi.org/10.1016/S0140 $-6736(12) 61079-4$.

4. Chan C, Ryerson CJ, Dunne JV, Wilcox PG. Demographic and clinical predictors of progression and mortality in connective tissue diseaseassociated interstitial lung disease: a retrospective cohort study. BMC Pulm Med. 2019;19(1):192. https://doi.org/10.1186/s12890-019-0943-2.

5. Ding Q, Luckhardt T, Hecker L, Zhou Y, Liu G, Antony VB, deAndrade J, Thannickal VJ. New insights into the pathogenesis and treatment of idiopathic pulmonary fibrosis. Drugs. 2011;71(8):981-1001. https://doi. org/10.2165/11591490-000000000-00000.

6. Lee JM, Yoshida M, Kim MS, Lee JH, Baek AR, Jang AS, Kim DJ, et al. Involvement of alveolar epithelial cell necroptosis in idiopathic pulmonary fibrosis pathogenesis. Am J Respir Cell Mol Biol. 2018;59(2):215-24. https://doi.org/10.1165/rcmb.2017-0034OC.

7. Willis BC, Liebler JM, Luby-Phelps K, Nicholson AG, Crandall ED, du Bois RM, Borok Z. Induction of epithelial-mesenchymal transition in alveolar epithelial cells by transforming growth factor-beta1: potential role in idiopathic pulmonary fibrosis. Am J Pathol. 2005;166(5):1321-32.

8. Radisky DC, Kenny PA, Bissell MJ. Fibrosis and cancer: do myofibroblasts come also from epithelial cells via EMT? J Cell Biochem. 2007;101(4):8309. https://doi.org/10.1002/jcb.21186.

9. Tanjore H, Xu XC, Polosukhin WV, Degryse AL, Li B, Han W, Sherrill TP, et al. Contribution of epithelial-derived fibroblasts to bleomycin-induced lung fibrosis. Am J Respir Crit Care Med. 2009;180(7):657-65. https://doi. org/10.1164/rccm.200903-0322OC.

10. Degryse AL, Tanjore H, Xu XC, Polosukhin VV, Jones BR, McMahon FB, Gleaves LA, Blackwell TS, Lawson WE. Repetitive intratracheal bleomycin models several features of idiopathic pulmonary fibrosis. Am J Physiol Lung Cell Mol Physiol. 2010;299(4):L442-452. https://doi.org/10.1152/ ajplung.00026.2010.

11. LiuTJ, Guo JL, XuX. CXC chemokine7 inhibits growth and migration of oral tongue squamous cell carcinoma cells, mediated by the epithelialmesenchymal transition signaling pathway. Mol Med Rep. 2017;16(5):6896903. https://doi.org/10.3892/mmr.2017.7441.

12. Ploenes T, Scholtes B, Krohn A, Burger M, Passlick B, Muller-Quernheim J, Zissel G. CC-chemokine ligand 18 induces epithelial to mesenchymal transition in lung cancer A549 cells and elevates the invasive potential. PLOS ONE. 2013;8(1):e53068. https://doi.org/10.1371/journal.pone.00530 68.

13. O'Beirne SL, Walsh SM, Fabre A, Reviriego C, Worrell JC, Counihan IP, Lumsden RV, et al. CXCL9 regulates TGF-beta1-induced epithelial to mesenchymal transition in human alveolar epithelial cells. J Immunol. 2015;195(6):2788-96. https://doi.org/10.4049/jimmunol.1402008.

14. Jin JJ, Dai FX, Long ZW, Cai H, Liu XW, Zhou Y, Hong Q, Dong QZ, Wang YN, Huang H. CXCR6 predicts poor prognosis in gastric cancer and promotes tumor metastasis through epithelial-mesenchymal transition. Oncol Rep. 2017;37(6):3279-86. https://doi.org/10.3892/or.2017.5598.

15. Jolly MK, Ward C, Eapen MS, Myers S, Hallgren O, Levine H, Sohal SS. Epithelial-mesenchymal transition, a spectrum of states: role in lung development, homeostasis, and disease. Dev Dyn. 2018;247(3):346-58. https://doi.org/10.1002/dvdy.24541.

16. Zhou W, Mo X, Cui W, Zhang Z, Li D, Li L, Xu L, Yao H, Gao J. Nrf2 inhibits epithelial-mesenchymal transition by suppressing snail expression during pulmonary fibrosis. Sci Rep. 2016;6:38646. https://doi.org/10.1038/ srep38646. 
17. Eckes B, Kessler D, Aumailley M, Krieg T. Interactions of fibroblasts with the extracellular matrix: implications for the understanding of fibrosis. Springer Semin Immunopathol. 1999;21(4):415-29.

18. Habiel DM, Hogaboam CM. Heterogeneity of fibroblasts and myofibroblasts in pulmonary fibrosis. Curr Pathobiol Rep. 2017;5(2):101-10. https ://doi.org/10.1007/s40139-017-0134-X

19. Geng J, Huang X, Li Y, Xu X, Li S, Jiang D, Liu Z, Dai H. Phosphatase and tensin homolog deleted on chromosome 10 contributes to phenotype transformation of fibroblasts in idiopathic pulmonary fibrosis via multiple pathways. Exp Biol Med. 2016;241(2):157-65. https://doi. org/10.1177/1535370215600100.

20. Epperly MW, Guo H, Gretton JE, Greenberger JS. Bone marrow origin of myofibroblasts in irradiation pulmonary fibrosis. Am J Respir Cell Mol Biol. 2003;29(2):213-24. https://doi.org/10.1165/rcmb.2002-00690C.

21. Hashimoto N, Jin H, Liu T, Chensue SW, Phan SH. Bone marrow-derived progenitor cells in pulmonary fibrosis. J Clin Invest. 2004;113(2):243-52. https://doi.org/10.1172/JCl18847.

22. Dow LE, Humbert PO. Polarity regulators and the control of epithelial architecture, cell migration, and tumorigenesis. Int Rev Cytol. 2007;262:253-302. https://doi.org/10.1016/S0074-7696(07)62006-3.

23. Bartley J, Julicher A, Hotz B, Mechsner S, Hotz H. Epithelial to mesenchymal transition (EMT) seems to be regulated differently in endometriosis and the endometrium. Arch Gynecol Obstet. 2014;289(4):871-81. https:// doi.org/10.1007/s00404-013-3040-4.

24. Sohal SS, Mahmood MQ, Walters EH. Clinical significance of epithelial mesenchymal transition (EMT) in chronic obstructive pulmonary disease (COPD): potential target for prevention of airway fibrosis and lung cancer. Clin Transl Med. 2014;3(1):33. https://doi.org/10.1186/s40169-014-0033-2.

25. Yilmaz M, Christofori G. EMT, the cytoskeleton, and cancer cell invasion. Cancer Metastasis Rev. 2009;28(1-2):15-33. https://doi.org/10.1007/s1055 5-008-9169-0.

26. Xia Y, Entman ML, Wang Y. Critical role of CXCL16 in hypertensive kidney injury and fibrosis. Hypertension. 2013;62(6):1129-37. https://doi. org/10.1161/HYPERTENSIONAHA.113.01837.

27. Chen G, Lin SC, Chen J, He L, Dong F, Xu J, Han S, Du J, Entman ML, Wang Y. CXCL16 recruits bone marrow-derived fibroblast precursors in renal fibrosis. J Am Soc Nephrol. 2011;22(10):1876-86. https://doi.org/10.1681/ ASN.2010080881.

28. Jiang L, Yang M, Li X, Wang Y, Zhou G, Zhao J. CXC motif ligand 16 promotes nonalcoholic fatty liver disease progression via hepatocyte-stellate cell crosstalk. J Clin Endocrinol Metab. 2018;103(11):3974-85. https://doi. org/10.1210/jc.2018-00762.

29. Ma Z, Yu R, Zhu Q, Sun L, Jian L, Wang X, Zhao J, Li C, Liu X. CXCL16/ CXCR6 axis promotes bleomycin-induced fibrotic process in MRC-5 cells via the PI3K/AKT/FOXO3a pathway. Int Immunopharmacol. 2020;81:106035. https://doi.org/10.1016/j.intimp.2019.106035.

30. Sisson TH, Mendez M, Choi K, Subbotina N, Courey A, Cunningham A, Dave A, et al. Targeted injury of type II alveolar epithelial cells induces pulmonary fibrosis. Am J Respir Crit Care Med. 2010;181(3):254-63. https ://doi.org/10.1164/rccm.200810-16150C.

31. Zhou L, Gao R, Hong H, Li X, Yang J, Shen W, Wang Z, Yang J. Emodin inhibiting neutrophil elastase-induced epithelial-mesenchymal transition through Notch1 signalling in alveolar epithelial cells. J Cell Mol Med. 2020;24(20):11998-2007. https://doi.org/10.1111/jcmm.15827.

32. Ando S, Otani H, Yagi Y, Kawai K, Araki H, Fukuhara S, Inagaki C. Proteinase-activated receptor 4 stimulation-induced epithelial-mesenchymal transition in alveolar epithelial cells. Respir Res. 2007;8:31. https://doi. org/10.1186/1465-9921-8-31.

33. Tan X, Dagher $H$, Hutton CA, Bourke JE. Effects of PPAR gamma ligands on TGF-beta1-induced epithelial-mesenchymal transition in alveolar epithelial cells. Respir Res. 2010;11:21. https://doi.org/10.1186/1465-9921-11-21.

34. Moeller A, Ask K, Warburton D, Gauldie J, Kolb M. The bleomycin animal model: a useful tool to investigate treatment options for idiopathic pulmonary fibrosis? Int J Biochem Cell Biol. 2008;40(3):362-82. https:// doi.org/10.1016/j.biocel.2007.08.011.

35. Tian R, Zhu Y, Yao J, Meng X, Wang J, Xie H, Wang R. NLRP3 participates in the regulation of EMT in bleomycin-induced pulmonary fibrosis. Exp Cell Res. 2017;357(2):328-34. https://doi.org/10.1016/j.yexcr.2017.05.028.

36. Weng CM, Li Q, Chen KJ, Xu CX, Deng MS, Li T, Zhang DD, et al. Bleomycin induces epithelial-to-mesenchymal transition via bFGF/PI3K/ESRP1 signaling in pulmonary fibrosis. Biosci Rep. 2020. https://doi.org/10.1042/ BSR20190756.

37. Luzina IG, Todd NW, Sundararajan S, Atamas SP. The cytokines of pulmonary fibrosis: much learned, much more to learn. Cytokine. 2015;74(1):88100. https://doi.org/10.1016/j.cyto.2014.11.008.

38. Biswas R, Bunderson-Schelvan M, Holian A. Potential role of the inflammasome-derived inflammatory cytokines in pulmonary fibrosis. Pulm Med. 2011;2011:105707. https://doi.org/10.1155/2011/105707.

39. Darash-Yahana M, Gillespie JW, Hewitt SM, Chen YY, Maeda S, Stein I, Singh SP, et al. The chemokine CXCL16 and its receptor, CXCR6, as markers and promoters of inflammation-associated cancers. PLOS ONE. 2009;4(8):e6695. https://doi.org/10.1371/journal.pone.0006695.

40. Hattermann K, Held-Feindt J, Ludwig A, Mentlein R. The CXCL16-CXCR6 chemokine axis in glial tumors. J Neuroimmunol. 2013;260(1-2):47-54. https://doi.org/10.1016/j.jneuroim.2013.04.006.

41. Kolb M, Bonniaud P, Galt T, Sime PJ, Kelly MM, Margetts PJ, Gauldie J. Differences in the fibrogenic response after transfer of active transforming growth factor-beta1 gene to lungs of "fibrosis-prone" and "fibrosis-resistant" mouse strains. Am J Respir Cell Mol Biol. 2002;27(2):141-50. https:// doi.org/10.1165/ajrcmb.27.2.4674.

42. Sheppard D. Transforming growth factor beta: a central modulator of pulmonary and airway inflammation and fibrosis. Proc Am Thorac Soc. 2006;3(5):413-7. https://doi.org/10.1513/pats.200601-008AW.

43. Shi K, Jiang J, Ma T, Xie J, Duan L, Chen R, Song P, et al. Pathogenesis pathways of idiopathic pulmonary fibrosis in bleomycin-induced lung injury model in mice. Respir Physiol Neurobiol. 2014;190:113-7. https:// doi.org/10.1016/j.resp.2013.09.011.

44. Zhang H, Newman DR, Sannes PL. HSULF-1 inhibits ERK and AKT signaling and decreases cell viability in vitro in human lung epithelial cells. Respir Res. 2012;13:69. https://doi.org/10.1186/1465-9921-13-69.

45. Ng-Blichfeldt JP, Alcada J, Montero MA, Dean CH, Griesenbach U, Griffiths MJ, Hind M. Deficient retinoid-driven angiogenesis may contribute to failure of adult human lung regeneration in emphysema. Thorax. 2017;72(6):510-21. https://doi.org/10.1136/thoraxjnl-2016-208846.

\section{Publisher's Note}

Springer Nature remains neutral with regard to jurisdictional claims in published maps and institutional affiliations.

Ready to submit your research? Choose BMC and benefit from:

- fast, convenient online submission

- thorough peer review by experienced researchers in your field

- rapid publication on acceptance

- support for research data, including large and complex data types

- gold Open Access which fosters wider collaboration and increased citations

- maximum visibility for your research: over $100 \mathrm{M}$ website views per year

At BMC, research is always in progress.

Learn more biomedcentral.com/submissions 